\title{
AMAZÔNIA E DIVERSIDADES LINGUÍSTICAS
}

\section{Resenha de:}

OLIVEIRA, E. S.; VASCONCELOS, E. A.; SANCHES, R. D. (Orgs.). Estudos linguísticos na Amazônia. Campinas: Pontes, 2019. (239p).

Augusto Gasparre Braga Façanha ${ }^{1}$ Antonio Almir Silva Gomes ${ }^{2}$

“A Amazônia é o palco mais eloquente do plurilinguismo brasileiro". A primeira informação do prefácio escrito por Margarida Maria Taddoni Petter para o livro Estudos linguísticos na Amazônia expõe a importância que esta região tem para a Linguística no Brasil. Organizado por Edna dos Santos Oliveira (Universidade do Estado do Amapá), Eduardo Alves Vasconcelos (Universidade Federal do Amapá) e Romário Duarte Sanches (Universidade do Estado do Amapá), a obra se propõe a divulgar produção científica em Linguística acerca da Região Norte, especialmente no estado do Amapá, que, de acordo com os organizadores, ainda carece de estudos e projeção quando comparado ao salto que outros estados da região tiveram em estudos linguísticos nos últimos anos.

O livro possui 239 páginas e é dividido em 11 capítulos. Em suas páginas, encontra-se uma lista bastante diversa de temas, como bilinguismo, documentação, etnografia e etnolinguística, discurso, política linguística, variação e contato linguístico, identidade, linguística histórica, descrição. Esses temas abrangem estudos linguísticos sobre Português Brasileiro (em diferentes modalidades), sobre a relação fronteiriça desta língua com a língua francesa, sobre distintas línguas indígenas. Os sete primeiros capítulos refletem estudos linguísticos desenvolvidos no e sobre o estado do Amapá. Os demais refletem estudos linguísticos concernentes aos estados do Pará e Amazonas.

O primeiro capítulo intitula-se $\mathrm{O}$ português falado por franceses em Oiapoque: considerações sobre a concordância nominal de número, de Celeste Maria de Rocha Ribeiro, e trata do uso do português brasileiro (PB) por franceses que residem no Oiapoque, cidade que, devido à sua localização geográfica fronteiriça com a cidade de Saint George (Guyanne), é palco de interação permanente entre brasileiros, franceses e indígenas. A autora indica que o escopo da pesquisa apresentada é o emprego de concordância nominal de número e que participaram do projeto "tanto os bilíngues que adquiriram o PB e o francês, simultaneamente, como os não-bilíngues que adquiriram o PB, após a aquisição da língua francesa (L1)" (p. 18). Na primeira seção, intitulada "Contato linguístico", a pesquisadora explica conceitos básicos sobre contato entre línguas e aquisição de segunda língua, tais como bilinguismo, transferência, interferência, interlíngua, code-mixing e codeswitching. Na segunda seção, "A região estudada", a autora fornece informações históricas e geográficas de Oiapoque, seu processo de ocupação e conflitos internacionais, salientando ser um ambiente de fluxo constante entre brasileiros e franceses. A este trânsito somam-se também os diversos povos indígenas da região. A terceira seção, "Situação linguística na região do Oiapoque", traz o panorama multilíngue da cidade, em que são falados francês, línguas indígenas (como Palikur, Kalinã e Kheuól) e outras línguas minoritárias de estrangeiros, sendo o PB a língua oficial e também a mais utilizada pela população. Em "Procedimentos metodológicos", quarta seção, Ribeiro descreve as etapas de sua pesquisa, "composta a partir da gravação do registro de fala de 13 indivíduos (08 homens e 05 mulheres)". Os registros se deram através de conversação entre a autora e os participantes, divididos em sexo, faixa etária e nível de escolaridade. Ao final, a autora relata traços do português L2 usado por franceses consonantes com o português L1 dos brasileiros, à exceção da marcação de plural em elementos à direita do núcleo da sentença (que tende a não ocorrer em

\footnotetext{
${ }^{1}$ Graduado em Letras - Português e Francês pela Universidade Federal do Amapá. Contato: augustogasparre@gmail. com.

2 Professor do Curso de Letras e do Programa de Pós-Graduação em Letras (PPGLET) da Universidade Federal do Amapá. Pesquisador CNPq (Universal 2016, Processo n. 424117/2016/9). Contato: a2sg@bol.com.br.
} 
PB L1) e a marcação por igual entre plural regular e irregular (que no PB L1 tende a acontecer mais no plural irregular).

O segundo capítulo, Bilinguismo entre os Karipuna do Amapá numa perspectiva geolinguística, de Romário Duarte Sanches, discorre sobre o grau de bilinguismo do povo Karipuna residente na Terra Indígena Uaçá, município de Oiapoque. É constituído de introdução e mais cinco seções: "Os Karipuna do Amapá", "Dialetologia, geolinguística e contato linguístico", "O contexto da pesquisa", "Descrição e mapeamento do perfil sociolinguístico dos Karipuna do Amapá" e "Considerações finais". Na primeira seção, o autor levanta o histórico do etnônimo "Karipuna", e descreve as tentativas por estudiosos e pesquisadores de compreender a origem do povo, sendo a hipótese mais provável a de uma junção de diferentes povos ao longo de séculos. Na segunda seção, o autor discorre sobre dialetologia, sobre o método geolinguístico como ferramenta para mapear as áreas dessas variantes e sobre o contato linguístico e seus fenômenos. A terceira seção descreve a metodologia empregada, bem como a pesquisa em si; o autor selecionou 36 falantes bilíngues indígenas, 4 em cada uma das nove aldeias nas TIs Uaçá, Juminã e Galibi, separados por sexo e faixa etária. Na quarta seção, a partir da conversação, os participantes autoavaliaram seu grau de bilinguismo em português e Kheuól em relação à fala, leitura, compreensão e escrita. Os dados revelam que a maioria dos Karipuna acredita dominar melhor o português do que o Kheuól, mesmo os mais velhos e os que ao aprenderam a língua crioula como L1. Na quinta seção, Sanches indica que, de acordo com os resultados da pesquisa, ocorre enfraquecimento da língua Kheuól na maioria das aldeias.

O Kheuól do Uaçá: perspectivas em pesquisa, de Glauber Romling da Silva e Gélsama Mara Ferreira dos Santos, aborda perspectivas de estudo e documentação para o Kheuól e o multilinguismo existente na TI Uaçá. Em "Breve histórico", os autores discorrem sobre a terra em questão, os povos que dela fazem parte - Galibi-Marworno, Karipuna e Palikur - e as línguas faladas na região - sobretudo Português, Kheuól e Parikwaki. Na sequência, os autores consideram que a língua Kheuól é gradativamente substituída pelo português entre Galibi-Marworno e Karipuna. Em "O Kheuól do Uaçá: língua crioula falada por indígenas", os autores apontam para essa língua como ainda pouco estudada no âmbito acadêmico, bem como tratam de características tipológicas marcantes de línguas crioulas em geral, seu nascimento através de contato abrupto entre línguas muito distintas e como sua ocorrência levanta questões sobre os processos históricos e culturais que levaram à sua formação. Em "Debate sobre línguas crioulas", Silva e Santos consideram que os parâmetros para identificação de uma língua crioula, sua origem e sua aquisição ainda estão longe de ser consenso entre pesquisadores, sendo um tema com muito a se pesquisar. Na sequência, "Tópicos gerais de pesquisa: possíveis contribuições do Kheuól do Uaçá", os pesquisadores lançam mais questionamentos sobre a crioulização, como o que favoreceria mudanças mais rápidas em línguas crioulas, o que torna sua sintaxe tão rígida, qual o grau de influência do substrato e do superstrato na língua etc. Também defendem que, como caso excepcional de uma língua crioula adotada como língua identitária por povos indígenas, o Kheuól tem muito a contribuir para estes estudos e que tal processo de apropriação da língua merece ser explorado. A seção seguinte é intitulada "Pesquisa, educação e revitalização: experiências com o Kheuól do Uaçá". Nesta seção, os autores relatam, tomando-se como referência ações desenvolvidas no âmbito de projeto realizado, a existência de problemas em relação à forma escrita do Kheuól - tanto para os Karipuna quanto para os Galibi-Marworno. Visando sanar esses problemas, foram realizadas oficinas em que professores indígenas discutiram uma reforma ortográfica, a partir das quais foram elaborados dois manuais de escrita para as duas variantes da língua, seis livros paradidáticos com histórias tradicionais (já narrados conforme as novas ortografias) e filmes documentais realizados por cineastas indígenas. Segundo Silva e Santos, “o projeto buscou desenvolver um enfoque que reforçasse o papel da escola indígena como promotora de uma atitude positiva sobre a valorização da língua de identidade". Em suas considerações finais, os autores consideram que a documentação linguística serve de base para o desenvolvimento de planos educacionais, produção multimídia diferenciados, gramáticas descritivas e estudos diversos. 
Edna dos Santos Oliveira e Eduardo Alves Vasconcelos escrevem o quarto capítulo, Dispersão e concentração: a constituição de áreas etnolinguísticas no Amapá, que versa sobre a proposta de duas áreas linguístico-culturais existentes no estado e seu processo histórico de difusão/propagação. Na primeira seção, "Contextualização", os autores explicam as duas áreas: uma ao norte, relacionada com as migrações derivadas da colonização francesa, e outra ao sul, consequência de dispersões populacionais em domínio historicamente português. A segunda seção, "Caracterização da área sul", como o título sugere, discorre sobre a área concentrada entre as cidades de Mazagão e Macapá, que recebeu muitos africanos (escravizados ou transferidos de outra colônia portuguesa) no processo de ocupação. Nesse cenário, os autores defendem que houve uma dispersão populacional com origem em Mazagão rumo a Macapá e que, entre as duas cidades e nos arredores, há uma perceptível concentração de festas e costumes de origem africana, como o batuque e o Marabaixo. Na seção seguinte, "Caracterização da área norte", verifica-se que nesta outra área, a partir da cidade de Oiapoque, há, além do componente africano, o componente cultural e linguístico indígena, tanto de populações nativas da região quanto de outras que ali se refugiaram durante as colonizações francesa e portuguesa. Os autores afirmam que, ao passo em que a área sul já é atestada como uma área etnolinguística consolidada, a hipótese da área etnolinguística norte ainda carece de estudos mais aprofundados e da verificação de traços linguísticos em comum entre os diferentes povos que dela fazem parte, sendo este um tema com muito a ainda ser explorado.

O quinto capítulo, O discurso religioso e a constituição do sujeito-fiel nos ladrões de Marabaixo, de Helen Costa Coelho, discute a composição do discurso religioso nos ladrões, versos improvisados de canções que tratam do cotidiano e de temas pertinentes à vivência quilombola. $\mathrm{Na}$ seção "Conceitos basilares da análise do discurso (AD) de linha francesa", a autora explica ideias importantes na compreensão do tema - discurso, ideologia e sujeito - a partir de Pêcheux, Althusser, Orlandi e Charaudeau e Mainguenau. Na segunda seção, "O discurso religioso", Coelho define esta modalidade discursiva como autoritária, no sentido de que "o interlocutor pregador é o porta-vOz de Deus e o interlocutor fiel manifesta-se simplesmente dizendo amém", não havendo troca comunicativa entre os dois. Este discurso também é classificado como impeditivo da reversibilidade - troca de lugar entre interlocutores - visto que não se pode discutir com a voz de Deus, apenas aceitá-la, e mesmo o pregador está preso à palavra divina para se manter legítimo. Na terceira seção, "A cultura do ciclo o Marabaixo no estado do Amapá", Coelho classifica o Marabaixo como uma manifestação religiosa sincrética, de orientação ligada ao catolicismo, porém com diversos ritos e práticas de matriz africana, e que, por isso, historicamente vive conflitos com o catolicismo oficial. "Metodologia e análise dos dados", quarta seção, apresenta o corpus - uma canção de Marabaixo e sua análise. A canção escolhida, "Maria de Deus", foi selecionada por, segundo a autora, possuir elementos de "discurso religioso católico sobre o sujeito fiel; a representação simbólica religiosa e o assujeitamento do sujeito-fiel a Deus". Tais aspectos são levados em conta na análise do ladrão.

Política e planificação linguísticas na fronteira franco-brasileira: contrassensos da perspectiva global, de Kelly Cristina Nascimento Day, aborda os resultados das políticas linguísticas de ensino de línguas estrangeiras na fronteira entre Brasil e Guiana Francesa. Divide-se em "Contextualização", "Fronteiras, línguas e políticas", "Balizas sociopolíticas e socioculturais da relação Amapá e Guiana Francesa", "Contrassensos político-linguísticos: entre o global e o local (glocal)" e "Considerações político-linguísticas finais". Na primeira seção, Day conceitua política linguística como toda ação tomada por uma autoridade ou agente social no sentido de regular/orientar o uso de diferentes línguas que existam numa mesma região. A autora também aponta que políticas linguísticas precisam ser tomadas em consonância com a vontade das populações envolvidas e que, nesse sentido, o Brasil parece historicamente andar na direção contrária, já que marcado por políticas impositivas. Na segunda parte, trata a área de fronteira como "marcada pelo encontro, pela heterogeneidade, pela diversidade", e que, nesse sentido, o estudo e o ensino de línguas nessas regiões têm que passar por uma profunda compreensão de sua realidade para que deem conta das necessidades dos falantes. Na terceira parte, o Amapá é destacado como único estado brasileiro a fazer

https://periodicos.unifap.br/index.php/letras

Macapá, v. 9, n. 4, $2^{\circ}$ sem., 2019 
fronteira com um território francófono. A partir disso, a autora afirma que, embora sempre houvesse interações entre guianenses e amapaenses, era marcante a lentidão em integrar socioeconomicamente as duas regiões de forma oficial, o que ocorre apenas na década de 1990 a partir do Acordo Quadro Franco-Brasileiro. A autora considera o período entre 1997 e 2002 como o de maior estreitamento de relações entre os países, com investimentos, por exemplo, em formação pedagógica em francês língua estrangeira (FLE), assessoria técnico-pedagógica, intercâmbio linguístico de docentes e discentes e infraestrutura. Posteriormente, entre 2003 e 2008, houve praticamente estagnação nos esforços do Amapá na aproximação e no ensino em francês, até que entre 2009 e 2012 houve reaproximação, também em virtude da Ponte Binacional em construção naquele momento. Na quarta seção, diante das informações levantadas anteriormente, a linguista critica a postura do Estado brasileiro ao diminuir drasticamente a importância de línguas locais no ensino em detrimento do inglês e do espanhol, e afirma que o que ocorre no Amapá é reflexo de uma política nacional equivocada. Na quinta parte, Day volta a salientar a importância em se pensar políticas linguísticas específicas para cada região do país.

As políticas linguísticas públicas educativas (PLPE): o caso das regiões fronteiriças do Brasil, de Marina Mello de Menezes Félix de Souza, busca a analisar os impactos das políticas públicas linguísticas do Governo Federal em regiões de fronteira, especialmente na fronteira Amapá-Guiana Francesa. Na primeira seção, "A política linguística pública (PLP) como campo de estudos”, Souza explica e fundamenta os conceitos de política pública e política linguística, propondo, a partir daí, abordar sua intersecção, nomeada pela autora como política linguística pública (PLP). Ela afirma haver três tipos de PLP: de regulação (PLPR), que regulamentam problemas comunicativos incentivando o plurilinguismo; educativa ou educacional (PLPE), intervenção em instituições de ensino; e de cooficialização ou nomeação (PLPC), que cooficializam (em municípios) ou patrimonializam (em estados) línguas. Souza ressalta que uma PLP pode conter elementos de mais de um tipo, e todas seguem as mesmas etapas: identificação do problema/área de atuação, formulação, implementação e análise. A autora considera a análise da PLP como de especial importância, embora poucos agentes político-administrativos deem atenção a ela. Na sessão seguinte, "As PLPR em região fronteiriça no Brasil e as recentes legislações que permeiam tais territórios", a autora destaca a importância do contato na formação identitária de fronteira e, nesse sentido, destaca o Projeto Escolas Interculturais de Fronteira - PEIF - firmado entre Brasil, Argentina e outros países sulamericanos e que objetivava a integração de diferentes culturas em áreas de fronteira. Embora promissor, conforme a pesquisadora, sua implementação sofreu problemas tais como a não valorização de modalidades fronteiriças, como o "portunhol", e a ausência de metas específicas para regiões fronteiriças no novo Plano Nacional de Educação (PNE). Souza discute então sobre o Amapá e destaca os mesmos fatos discutidos sexto capítulo: a priorização do inglês e a progressiva exclusão do francês como língua estrangeira nas escolas. Cita também a resistência dos professores de francês do estado em face dessa situação.

O capítulo seguinte, de Ednalvo Apóstolo Campos, inicia o conjunto de artigos que discutem estudos linguísticos acerca de línguas nos estados do Pará e Amazonas. Intitulado O contato linguístico na Amazônia e o português afro-indígena, o artigo trata da variedade "afro-indígena" do português brasileiro falado em parte da Amazônia. Na introdução, o linguista situa a perspectiva do trabalho como de contato linguístico, e o português brasileiro como um continuum entre o português vernacular brasileiro (PVB) e o culto (PB). Na seção "Considerações sobre o português brasileiro", Campos afirma que o Brasil vive uma situação de diglossia, na qual o PVB é a variante estigmatizada e o PB é a valorizada, havendo "uma espécie de fosso que separa as variedades". Dentro da variedade PVB há dialetos e também variedades específicas de um contexto histórico e social, como o português afro-brasileiro de quilombos. Na seção seguinte, "O contato linguístico na Amazônia", o autor situa a Amazônia como peculiar por sua heterogeneidade. Conforme Campos, o contato de populações portuguesas e indígenas durante período colonial resulta no Nheengatu, a Língua Geral Amazônica (LGA), usada como língua franca e também língua materna de vários povos da região. Por outro lado, há também a influência de línguas africanas a partir do

https://periodicos.unifap.br/index.php/letras

Macapá, v. 9, n. 4, $2^{\circ}$ sem., 2019 
século XVII e a vinda de negros de colônias inglesas do Caribe para Belém no século XIX, bem como centenas de povoados quilombolas. Numa sub-seção, Campos explora a comunidade quilombola Jurussaca, no Pará, onde ocorre a variedade do português afro-indígena sobre o qual se refere o artigo. Os moradores são miscigenados de indígenas e quilombolas, e seu português tem elementos únicos, como pronome ressumptivo duplo ("ele se mudouse pra cá") e construções como "ele nós ajudou". O mesmo fenômeno, de acordo com o pesquisador, ocorre em outras comunidades com origens semelhantes. $\mathrm{Na}$ terceira seção, "A morfossintaxe do português afro-indígena em cotejo com outras variedades", o autor, baseado em Campos (2014), destaca características do uso pronominal nesta variedade, como: objeto duplo sem preposição no objeto indireto; clítico inerente "se" e duplo emprego de "se"; pronomes atemáticos "eu e "ele" ("ele é de cobre ele"); e uso de pro-forma "esse(a)/aquele(a) um(a)". A partir daí, são traçadas semelhanças desta modalidade com variedades africanas de português, como o cabo-verdiano, o angolano e o afro-brasileiro em comunidades quilombolas de Cametá-PA.

Em Línguas indígenas no Baixo Tapajós: notas preliminares sobre estratégia política e linguística em contexto de afirmação étnica, Sâmela Ramos da Silva discute a retomada das línguas Nheengatu e Munduruku por povos indígenas na região do Baixo Amazonas, como forma de preservar sua identidade. Em "Primeiras palavras", a autora nota que, a despeito da conquista dos movimentos indígenas com a Constituição de 1988, estes povos "ainda convivem com a espoliação de suas terras, culturas, línguas" (p. 179) por não-indígenas. Na segunda parte, "O panorama étnico no Baixo Tapajós", temos que a região engloba os municípios de Santarém, Belterra e Aveiro, compreendendo 13 grupos indígenas, todas sem demarcação oficial de terras. Segundo a autora, estes povos passaram a se mobilizar etnicamente após a morte de um importante pajé da região, Laurelino Cruz, e reivindicaram status indígena, solicitando marcação de suas terras e resgatando as línguas Nheengatu e Munduruku como línguas ancestrais. Na terceira parte do capítulo, "Repensando conceitos hegemônicos", a autora defende que a adoção e a valorização de uma língua identitária é uma forma de resistência indígena para que sua identidade não seja deslegitimada, visto que, de acordo com uma visão colonial hegemônica, um índio seria "menos índio" ou mesmo "não índio" caso não tenha uma língua diferente do português. A pesquisadora aponta que identidade, cultura, etnicidade e língua são construtos sociais e que, por isso, o resgate destes elementos por povos indígenas se dá principalmente como estratégia de resistência. A quarta parte, "Processos de afirmação étnica e a relação com a língua indígena", é dividida em dois sub-tópicos: o primeiro sobre o resgate do Munduruku pela aldeia de Taquara, onde a língua deixara de ser usada; o segundo, sobre a apropriação do Nheengatu pelos demais povos do Baixo Tapajós. No caso de Taquara, a autora afirma que os Munduruku da região se esforçam em aprender a língua e se reafirmar enquanto povo, tanto pela pressão da sociedade não-indígena, quanto pelo valor que é conferido a essa língua em nome das origens e tradições de Taquara. Assim, destaca-se a escola indígena como ambiente de ensino e de reprodução de músicas e expressões na língua ancestral. Já no caso do Nheengatu, o trabalho de revitalização ainda está em curso, apoiado, sobretudo, na formação de professores de Nheengatu pela Universidade Federal do Oeste do Pará (UFOPA).

Raynice Geraldine Pereira da Silva discorre sobre Adverbiais em Mawé. Na introdução do artigo, a autora apresenta Sateré-Mawé (também referida como Mawé) como única língua da família Mawé, inserida no tronco Tupi e falada na terra indígena Andirá-Marau, médio Amazonas. Segundo a autora, a língua é classificada como de "sistema ativo não ativo" para nomes e verbos, não possuindo classe gramatical de adjetivo. No que confere a classes, são encontradas na língua: verbos, nomes, advérbios, pronomes, partículas e auxiliares. Na segunda seção, "Tipologia dos advérbios em Mawé", a pesquisadora aponta que os advérbios se dividem em: locativos (proximais, mediais e distais), temporais, interrogativos e numerais (cardinais, quantificadores e dimensionais). Na terceira seção, "A sintaxe das construções adverbiais em Mawé", Silva afirma haver quatro tipos de orações adverbiais: locativas; de assunto/causa; de finalidade; e temporais. A autora indica que num contexto de transitividade o advérbio obedece a ordem Advérbio-Verbo-Objeto, determinada pela posição dos argumentos. A pesquisadora resume os resultados da pesquisa na sua conclusão.

https://periodicos.unifap.br/index.php/letras

Macapá, v. 9, n. 4, $2^{\circ}$ sem., 2019 
Último capítulo, Revisitando o proto-juruna: a reconstrução da série de oclusivas orais, de Fernando Orphão de Carvalho, volta-se ao trabalho de Fargetti e Rodrigues (2008) - referidas posteriormente pelo autor como "FR (2008)" - especialmente relacionado à parte do sistema fonológico do proto-juruna (PJ). Em “As línguas Yudjá e Xipáya”, estas línguas são apresentadas como as únicas remanescentes da família Juruna, com muitas características em comum: inventários fonológicos quase idênticos, nasalidade vocálica contrastiva, ataque silábico e coda não permitidos. Em "Os desenvolvimentos de PJ *p", é demonstrado que o som p em Xipáya por vezes corresponde ao som h em Yudjá em algumas palavras de mesma origem, como em ukápa do Xipáya e ukáhá do Yudjá. De acordo com Carvalho, FR (2008) defendem que o protofonema ${ }^{*} \mathrm{p}$ sofreu cisão em p e h em Yudjá quando sucedido de vogais contextuais a, i e u. Carvalho, contudo, propõe que, no caso de a, a cisão seria motivada por um nominalizador *-(a)pa existente no PJ, visto que a mudança só foi observada em nomes, predominantemente de natureza instrumental, e que há um nominalizador circunstancial -aha em Yudjá que costuma resultar em nomes instrumentais. Segundo o autor, a mudança fonética poderia ter ocorrido ou por analogia com outro morfema parecido ou por empréstimo dialetal. Quanto aos casos de i e u, é levantada a possibilidade dos sons ${ }^{*} \mathrm{p}$ e ${ }^{*} \mathrm{p}^{\mathrm{h}}$ estabelecerem alofonia ao precederem ${ }^{*} \mathrm{u}$ no PJ e que, progressivamente, tal fonema foi debucalizado, resultando em *h. Na seção seguinte, "Correspondências das oclusivas coronais", o autor defende que a presença de africadas em Yudjá e sua ausência em Xipáya é explicada por dois processos diferentes: a fusão dos fonemas *t e *t $\int$ em Xipaya, resultando em t, e a cisão de *d em d e dz em Yudjá. Finalmente, na seção "As correspondências das oclusivas velares", Carvalho discorda de PR (2008) quanto à existência de *k e *g no PJ, tendo tal contraste se perdido nas línguas subsequentes. $O$ linguista sustenta que havia apenas o fonema $*_{k}$, não havendo evidência forte o bastante para apoiar a hipótese de contraste *k e $*_{\mathrm{g}}$.

A diversidade de temas que constitui Estudos Linguísticos na Amazônia o torna leitura importante àqueles cujo interesse de pesquisa (ou de curiosidade) recaia sobre a Amazônia brasileira. Ao tempo em que ilustra a diversidade de temas - conforme indicamos no início desta Resenha, relacionada a bilinguismo, documentação, etnografia e etnolinguística, discurso, política linguística, variação e contato linguístico, identidade, linguística histórica, descrição - o livro nos faz pensar uma imensidão de novas possibilidades de pesquisas. A este respeito, por exemplo, o primeiro capítulo tratou da relação de falantes da língua francesa com o Português Brasileiro na região Oiapoque, cenário que nos faz pensar, dentre tantos outros, na necessidade de estudos de contatos, de identidades, de usos, de aprendizado, de ensino de línguas. Nesse conjunto de estudos, encontramse não apenas estas duas línguas indo-europeias, mas também as línguas indígenas da região (Kheuól Galibi-Marworno, Kheuol Karipuna, Palikur), as línguas dos emigrantes que circulam regularmente pela fronteira (Chinês, Árabe, Espanhol, Inglês etc.), bem como as línguas crioulas advindas do outro lado da fronteira (Crioulo Francês, Taki-Taki). Os estudos linguísticos nessa direção nos ajudarão a melhor compreender o cenário multilíngue inerente à cidade de Oiapoque, mas também a melhor compreender o cenário multilíngue inerente à região amazônica. Nessa região, situação semelhante à do município de Oiapoque pode ser atestada no Complexo do Tumucumaque onde, grupos falantes de línguas Karíb (Aparai, Wayana, Tiriyó, Kaxuyana, Akuriyó, Xikyana) têm contato, inclusive, com a língua holandesa em virtude de relações parentais com indígenas que vivem no Suriname. Outros casos podem ser pensados a partir da fronteira amazônica com países em que a língua oficial é Espanhol, tais como Venezuela, Colômbia, Peru, Bolívia. Nesse sentido, temos que as fronteiras internacionais do Brasil, pela Amazônia, geram cenários linguísticos que ainda têm muito a contribuir com a ciência Linguística.

O segundo capítulo, ao chamar a atenção para o "bilinguismo" entre os Karipuna, nos permite pensar acerca da recepção, pela população urbana de Oiapoque, do Português Brasileiro usado por aquela população indígena, conforme cenário apresentado por Santos e Gomes (2018). De acordo com Santos e Gomes, op. cit., trata-se de uma modalidade da língua sobre a qual recaem 
estereótipos, estigmatizações advindas da população oiapoquense. O "bilinguismo", as identidades que se constroem no uso desta ou daquela língua (materna, adicional, de herança, etc) constituem-se interessantes para questões de políticas linguísticas, tema também presente em Estudos Linguísticos na Amazônia.

Dada à infinitude dos fenômenos gerados, é impossível uma lista completa de novas possibilidades de estudos linguísticos a partir dos temas presentes no livro. Por esse motivo, encerramos as discussões aqui apresentadas com a observação do terceiro capítulo do livro, que chama a atenção, dentre outros, para a documentação linguística e seus efeitos na escola indígena. O artigo nos faz pensar, sobretudo, que é possível associar de maneira exitosa documentação linguística à sala de aula; igualmente, nos faz pensar na necessidade emanada da Educação Escolar Indígena de que as pesquisas linguísticas que realizamos atinjam (didatizadas) a escola das comunidades indígenas. Essas pesquisas devem contribuir com o Ensino de Línguas em Contexto Indígena (ELCIND) ao permitir que conhecimentos do próprio povo permeiem a sala de aula. $\mathrm{O}$ mesmo ocorreria com os estudos linguísticos gerados acerca do Português Brasileiro em uso por populações quilombolas como aquele descrito por Ednalvo Apóstolo Campos. Para além dos temas mencionados anteriormente, portanto, as pesquisas tratadas em Estudos Linguísticos na Amazônia permitiriam, aos interessados no tema, pensar em ensino de línguas em suas diferentes faces.

Finalmente, mas não menos importante, pelos sete artigos iniciais, o livro chama a atenção para a Linguística que tem sido desenvolvida no estado do Amapá; dá ao leitor compreensão da diversidade de interesses de pesquisa empreendidos pelo grupo de linguistas residentes no estado em virtude de atuação profissional na Universidade Federal do Amapá e na Universidade do Estado do Amapá. Que o grupo em questão seja cada vez mais profícuo e, assim, contribua com entendimentos acerca dos fenômenos linguísticos na Amazônia; nos termos de Petter, "[...] palco mais eloquente do plurilinguismo brasileiro"!

\section{REFERÊNCIAS}

CAMPOS, E. A. A sintaxe pronominal na variedade afro-indígena de Jurussaca: uma contribuição para o quadro da pronominalização do português falado no Brasil. Tese de doutorado: Universidade de São Paulo, 2014.

FARGETTI, C. M.; ROGRIGUES, C. R. Consoantes do Xipaya e do Juruna: uma comparação em busca do Proto-Sistema. Alfa 52 (2): 2008, p. 535-563.

SANTOS, M. C. dos; GOMES, A. A. S. Português brasileiro falado pelo povo Karipuna: uma forma de uso que sofre preconceito linguístico. Revista Brasileira de Línguas Indígenas, v. 1, n. 2, 2018, p. 63-71.

Recebido em: 10/10/2019

Aprovado em: 21/11/2019 